\title{
OS MODERNINHOS DO SERTÃO \\ A TRAIÇÃO DA TRADIÇÃo E O CULTO À MODERNIDADE ${ }^{1}$
}

Bruno Goulart Machado Silva, UFRN

\begin{abstract}
Resumo: 0 presente trabalho discute a ideologia da sociedade moderna e como os países de terceiro mundo adotaram esses modelos ideológicos nos seus projetos nacionais. Esses modelos criam pedagogias que geram fronteiras internas e montam diferentes estratégias de performances na sociedade nacional. 0 caso brasileiro, com suas narrativas dualistas, montou uma ideologia híbrida, que se polariza em narrativas expressas em binaridades, como: moderno-tradicional, desenvolvidosubdesenvolvido, sertão-litoral, essa última oposição ó o foco apresentado aqui. 0 pensamento social no Brasil sempre representou o sertão como uma região concreta: Nordeste, Centro-oeste, Norte de Minas Gerais e partes do Sudeste foram ditos e vistos como sertão. É o caso também do estado de Goiás que desde as bandeiras foi representado como lugar vazio, fronteira a ser ocupada e civilizada, local de formas arcaicas de poder político, marcado por relações personalistas. Mas o sertão é uma região imaginada, não cartografada e construída discursivamente, de modo que as representações sobre o sertão são variadas. Contemporaneamente, em Goiás, as representações de modernidade querem deslocar o sertão para "mais além". Através de um trabalho empírico com universitários goianos, pretende-se discutir as representações do moderno e do tradicional e como estas instâncias estão imbricadas.
\end{abstract}

Palavras-chave: identidade, sertão, modernidade.

Este artigo surgiu a partir da monografia apresentada para obtenção do grau de bacharel em ciências sociais no ano de 2010 pela UFG. A monografia foi resumida e suprida em alguns pontos para adquirir o formato atual. Contudo buscamos não alterar a ideia central da proposta de monografia.

O que se segue é uma tentativa de interpretação do deslocamento do sertão de Goiás, mapeando o discurso, ressaltando seus conteúdos e percebendo como são performatizados. E também como esse movimento de realocamento do sertão se insere num contexto onde o desejo de modernidade, e de ser moderno, surge para os países de terceiro mundo como a única forma de redenção para estigmas como de sertão, subdesenvolvido etc. $\mathrm{O}$ texto se constitui de três momentos; o primeiro trata sobre a configuração particular adquirida pelos países de terceiro mundo, e como essa configuração tem uma consequência no Brasil, criando narrativas dualistas. E não

\footnotetext{
${ }^{1}$ Trabalho apresentado na $27^{\mathrm{a}}$. Reunião Brasileira de Antropologia, realizada entre os dias 01 e 04 de agosto de 2010, Belém, Pará, Brasil.
} 
apenas insere o panorama da etnografia, mas contextualiza o próprio autor e o enfoque privilegiado por este. A segunda parte diz respeito a um tipo de dualismo geográfico expresso nas narrativas nacionais, onde um dos polos é o sertão. Procuramos argumentar de forma breve como o sertão foi construído, de maneira geral, para então apresentar o caso particular do estado de Goiás. Por fim, apresentamos uma etnografia de autoria própria que mostra como esse discurso é performatizado no dia a dia. Como a modernidade se justifica discursivamente para esse grupo pesquisado - jovens que nasceram a partir dos anos 1980, que vivem em Goiânia e cursam Ciências Sociais - foi o interesse principal aqui exposto. Procuramos mostrar como esse discurso se vincula com o contexto exposto e suas implicações para a sociedade nacional.

Segundo Quijano, ao mesmo tempo em que o racismo se justificativa no âmbito discursivo, o trabalho escravo era utilizado para fomentar o ego europeu, estabelecendo um sistema-mundo moderno/colonial e sua hegemonia. Sistema-mundo porque toda a população terrestre foi de alguma forma afetada pela expansão do capitalismo, e moderno/colonial porque a modernidade hegemônica europeia precisava do sistema colonial para sustentar seus projetos universais.

Como se sabe, o controle do tráfico comercial mundial pelos grupos dominantes, novos ou não, nas regiões do Atlântico onde tinham suas sedes, impulsionou um novo processo de urbanização nesses lugares, a expansão do tráfico comercial entre eles, e desse modo a formação de um mercado regional crescente integrado e monetarizado graças ao fluxo de metais preciosos procedentes da América. Uma região historicamente nova constituía-se como uma nova id-entidade geocultural: Europa, mais especificamente Europa Ocidental. Essa nova Identidade geocultural emergia como a sede central do controle do mercado mundial. No mesmo movimento histórico produzia-se também o deslocamento de hegemonia da costa do Mediterrâneo e da costa ibérica para as do Atlântico Norteocidental. (Quijano, 2005, p.233).

Benedict Anderson chama atenção para o fato que o surgimento dos movimentos nacionalistas na Europa coincidiu em grande parte com a independência das Américas (1997, p.107). É importante notar que apesar dos países europeus serem 
adotados como modelos de nação e se legitimarem numa certa antiguidade, sua origem é contemporânea ao surgimento dos projetos nacionais das Américas. O que faz sentido se pensarmos que a nacionalidade era um novo modelo de sociedade, uma nova questão que se colocava em pauta, mas que foi um modelo de organização social universalizado para o mundo; o que implicou que a única saída possível por parte das Américas era se constituírem como Estados nacionais após a independência, pois só assim teriam voz política para combater a colonização, do contrário seriam apenas "selvagens" e "tribais". As elites desses países também estavam comprometidas com esses projetos universais, buscando de qualquer maneira colocá-los em prática, e se auto reconhecendo como parte dessa modernidade.

Mas se o surgimento do nacionalismo coincide nas Américas e na Europa não podemos dizer o mesmo dos caminhos seguidos pelos dois. Anderson aponta que:

\footnotetext{
o caráter populista dos primeiros nacionalismos europeus, mesmo quando liderados demagogicamente pelos grupos sociais mais retrógrados, foi mais profundo do que os americanos: a servidão tinha de sumir, a escravidão legal era inimaginável - quando menos porque o modelo conceitual assim o exigia irretorquivelmente. (Anderson, 1997, p.127)
}

O que não acontece na América. Assim, se na Europa a escravidão era inimaginável diante de uma realidade nacional, nas Américas ela continuou a existir sem grandes contradições. Isso se deu porque o racismo continua a ser uma realidade sociológica nas antigas colônias mesmo depois da sua independência; as justificativas de dominação dos negros e índios permaneceram. E quando se pensava em "incluí-los", eram encarados como um desafio de civilizar primitivos. Assim o negro e o índio enfrentam restrições de inúmeras espécies na participação da sociedade nacional. $O$ projeto nacional não inclui esses povos nas suas narrativas nem mesmo como problema social ${ }^{2}$. Políticas indigenistas e para negros começam a surgir há algumas décadas e são até hoje um desafio para o Estado nacional (Quijano, 2003; Dussel, 2004).

A burguesia imperialista e a burguesia nacional não possibilitaram a democratização dos países da América Latina. Ao adotarem modelos eurocêntricos e norte-americanos levaram às populações indígenas a uma constante redução e

2 A própria ideia de problema social já é uma forma de dominação, porque ao tratar esses grupos sociais como problemas os encaram como empecilhos ao desenvolvimento da nação. 
mantiveram a escravidão negra como principal fonte de produção após a independência.

\begin{abstract}
Por tudo isso, a colonialidade do poder estabelecida sobre a ideia de raça deve ser admitida como um fator básico na questão nacional e do Estado-nação. O problema é, contudo, que na América Latina a perspectiva eurocêntrica foi adotada pelos grupos dominantes como própria e levou-os a impor o modelo europeu de formação do Estado-nação para estruturas de poder organizadas em torno de relações coloniais. (Quijano, 2004, p.269)
\end{abstract}

Franz Fanon chama a atenção para o fato da impossibilidade da construção de Estados-nações a partir de uma revolução burguesa nos países de terceiro mundo:

\footnotetext{
Em su aspecto decadente, la burguesía nacional será considerablemente ayudada por las burguesías occidentales que se presentan como turistas enamorados del exotismo, de la caza, de los casinos.[...] Como no tiene ideas, como está encerrada en sí misma, aislada del pueblo, mimada por su incapacidad congénita para pensar en la totalidad de los problemas en función de la totalidad de la nación, la burguesía nacional va a asumir el papel de gerente de las empresas occidentales y convertirá a su país, prácticamente, em lupanar de Europa (1986, p 141)
}

E não apenas converte a burguesia nacional em gerente das empresas, mas também gestores do projeto euro-centrado de modernidade. Isso leva a duvidar da própria subalternidade que os países de terceiro mundo ocupam enquanto totalidades, porque a implementação desses projetos é fruto de um próprio desejo das diversas elites em se comprometer com a ideologia do ocidente, sejam essas elites locais ou nacionais.

Quijano e Fanon apontam para a impossibilidade de se criar um Estadonação "completo" através de uma revolução burguesa. O projeto nacional burguês atualizou as formas de dependência, legitimando-as diante um novo contingente mundial. E ao dar esse passo em direção à colonialidade e implementar estratégias de unificação nacional sobre o domínio de uma parcela da sociedade nacional foram provocadas reações que resultaram na fratura das sociedades nacionais, "y es desde estas fracturas peculiares que partieron, para cada caso, culturas distintivas, tradiciones 
reconocibles y identidades relevantes en el juego de intereses políticos" (Segato, 2007, p. 47). Tal processo é o que Segato chama de formação de alteridades nacionais, fomentadas no processo histórico da construção da nação.

Esse projeto criou nos países latino-americanos e africanos narrativas nacionais que negociam o caráter "incompleto" da maioria dos países de terceiro mundo. Essas pedagogias negociam o subdesenvolvimento de diversas maneiras, como a criação de narrativas dualistas: apontando como fonte do atraso certas populações (índios e negro) ou através da alocação de certos espaços à origem desse atraso (caso do Brasil e Argentina). Os Estados nacionais criam suas próprias narrativas nas quais negociam discursivamente os estigmas do "subdesenvolvimento", "atraso", "primitivismo".

Os fragmentos, retalhos e restos de vida cotidiana devem ser repetidamente transformados nos signos de uma cultura nacional coerente, enquanto o próprio ato de performance narrativa interpela um círculo crescente de sujeitos nacionais. Na produção da nação como narração ocorre uma cisão entre a temporalidade continuísta, cumulativa, do pedagógico e a estratégia repetitiva, recorrente, do performático. É através deste processo de cisão que a ambivalência conceitual da sociedade moderna se torna lugar de escrever a nação. (Bhabha, 2007, p.207)

A escrita da nação negocia o estigma do subdesenvolvimento. Bhabha chama atenção para o fato de que o "povo como uma forma de interpelação emerge do abismo da enunciação onde o sujeito se divide, o significante "desaparece gradualmente" e o pedagógico e o performático são articulados de forma agonística" (2007, p. 217).

$$
* *
$$

Este trabalho se insere nesse contexto: o desejo por modernidade e as narrativas dualistas das nações do terceiro mundo. $\mathrm{O}$ caso brasileiro reviveu esses dualismos de diversas formas. O caso específico tratado aqui é a dualidade geográfica expresso na dicotomia sertão-litoral, e como o desejo de reverter o estigma do sertão cai numa celebração da modernidade, entendida aqui como um desejo de ser reconhecido num modelo que se cria através de relações hierárquicas. 
O pensamento social do Brasil sempre representou o sertão como uma região concreta: Nordeste, Centro-oeste, Norte de Minas Gerais e até mesmo partes do Sudeste foram ditas e vistas como sertão. Sua variedade textual ${ }^{3}$ leva a refletir sobre seu caráter móvel e fluido. O sertão é muito mais uma categoria sobre a qual se pensa $a$ partir, do que sobre. O nativo dificilmente estranha o sertão. Mesmo o habitante por excelência do sertão, o sertanejo, não se percebe como um grupo social, o homem do sertão é plural, o sertanejo é o jagunço; o roceiro; o boiadeiro; o camponês, como bem lembrou Mireya Suárez (1998), o sertanejo é uma maneira de opor o homem civilizado ao homem definido como tradicional. A classificação 'sertaneja' não remete a um grupo social específico, com papéis sociais estabelecidos, o sertanejo é o sertão.

As narrativas do sertão são inúmeras, desde aquelas produzidas por 'homens de letras' até as 'populares'. Essa infinidade de discursos se entrelaçam, às vezes de forma ambígua, ora remetendo a um lugar de mazelas, ora a um local onde se encontram a 'fartura' e o 'sossego', ou, o caso do sertão como fronteira de expansão, a um lugar vazio a ser modernizado ${ }^{4}$.

O sertão é uma confluência de discursos, um fluxo interminável de representações, que classifica as regiões que ocupa, pois "é a própria condição de periferia que constitui a região como fenômeno" (Sena e Lima, 2005, p.36). Regionalizar pessoas, lugares, expressões artísticas é forma de subalternizar, depreciar, marcar a ferro com o viés da negatividade, do agônico. A região é expressão do atraso, do particular, do imutável, enquanto o moderno é universal, dinâmico. Mas a ideia que se tem do tradicional como imutável, como preservador mimético de práticas culturais, é forma de instituir o tradicional, negando dinâmica aos processos sociais e identitários vistos como arcaicos. E ao negar essa dinâmica, nega-se voz política ao 'atrasado' em favor da hegemonia do que foi chamado anteriormente de identidade-norma. O que por sua vez relega essas identidades "a um passado distante do qual suas vozes parecem estar emergindo num clamor despótico, completamente extemporâneo" (Rutherford e Bhabha, 1998, p.39).

Relegar então o outro a um enclausuramento cultural, onde ser tradicional é

3 Textual empregado aqui no sentido de uma leitura da imagem, que vai desde obras literárias até propaganda de produtos. Para um desenvolvimento melhor da ideia ver Johnson, Richard em Da Silva, Tomaz Tadeu da Silva (2006, p 72).

4 Não é preciso ir longe para perceber o sertão como fronteira, basta assistir aos horários políticos para governador do Tocantins e de Goiás. 
sinônimo de preservação mimética da cultura de geração para geração, é uma forma de não querer enxergar sua dinâmica. Congelar as manifestações tidas como arcaicas é uma forma de dizer que o regional é atrasado, de colocá-lo numa temporalidade e espacialidade distantes, como se pensa frequentemente. Ser moderno, em oposição, seria 'viver na velocidade da luz'. Isso institui a região à inevitabilidade da dependência da nação/civilização, que seria responsável por introduzir o moderno nos solos do sertão.

Segundo Sena,

\begin{abstract}
"A partir de alguns espaços definidos como a origem ou o centro da nação e, portanto, da civilização - o litoral, o sul essas narrativas classificam como região os espaços periféricos ou decadentes a serem totalizados pela nação.[...] diferentes definições de região em distintas tradições disciplinares ressaltam esse caráter subordinado da região relativamente a uma totalidade que a contém, seja uma área geográfica, uma área cultural, um território nacional ou um modo de produção" (SENA, 2003, p.114).
\end{abstract}

Goiás é sertão, é reconhecido como espaço periférico a ser tomado e ocupado pelo modo de produção capitalista, ou pelos costumes modernos e relações individualistas. O que pretendemos agora é problematizar como se fixaram imagens e dizibilidades a respeito de Goiás por escritores regionais, viajantes, governadores de província, historiadores e cientistas sociais.

'Sertão' foi primeiro usado para designar um espaço no Brasil, pela carta de Pedro Vaz de Caminha, que localiza o sertão como tudo aquilo que estava pra lá do litoral, toda a porção de terra adentro, tudo que era 'mato', 'selvagem' e 'desconhecido'. É com os relatos de viajantes do interior do país e dos governadores de província que o recorrente sertão como lugar do sobrenatural, atrasado, decadente é chamado a povoar o imaginário nacional. Estes narradores de ficção estão preocupados com "dizer a verdade da região". Recolhem-se lendas, tipos e costumes que "constituem" o lugar. Mas esse "recolher" não é inocente, ele classifica, hierarquiza e subalterniza o sertão e o sertanejo.

No caso de Goiás, esses escritos servem de base para toda produção intelectual a respeito de Goiás, sem restrições, seja como fonte documental ou como base para se estudar o processo de diferenciação regional (Chaul,1997).

Os viajantes que passavam em Goiás vinham com uma perspectiva europeia (quando eram estrangeiros) ou litorânea, e tinham como valor central o progresso. 
Produzem imagens que vão do isolamento devido à situação das estradas e à falta de vias fluviais e férreas, ao ócio da população que é apática e vive na conformidade, à mestiçagem como fator degenerativo do povo e por isso 'inviável civilizatoriamente'. Habituados com os super-povoamentos e com as riquezas do ouro, o que esses viajantes não puderam notar é que, primeiro, o ouro que tanto reluzia nos seus lares tinha saído dos confins das colônias mundo afora e não as enriquecido; e, em segundo, Goiás obedecia a uma lógica de crescimento particular. Essas imagens de isolamento e decadência vão ser trilhadas por gerações de historiadores, instituindo assim o sertão como o lugar por excelência do arcaico.

Esse caráter documental, dos relatos dos viajantes, de registro da região é herdado pela literatura regionalista do século XIX. Segundo Antônio Candido, o romance regionalista constituiu "uma das principais vias de autodefinição da consciência local" (1967, p.133-4), mas no final do século XIX transforma-se no "conto sertanejo', o qual o autor julga como gênero pretensioso e artificial porque trata de maneira pitoresca o próprio país. Este predominou como divulgador da temática regional até os anos 30. A partir daí, o regionalismo se torna um gênero secundário, onde outras expressões da temática regional tomam a cena. É o caso do romance social, produzido no Nordeste a partir dos anos 30, com nomes como o de Graciliano Ramos e Jorge Amado, e o super-regionalismo a partir dos anos 50, com Bernardo Élis e Guimarães Rosa.

Mas a eficácia simbólica dessa literatura sertaneja, tida por Candido como artificial, não diminui devido à pouca qualidade estética dessas obras. Por isso, para uma análise discursiva dessas obras adotarei a classificação de Vicentini(1998), na qual as expressões literárias que tratam da temática regional são enquadradas na literatura regionalista, como forma de não diferenciar autores como Bernardo Élis (visto como hiper-regionalista) de outros escritores regionalistas. É sem dúvida inquestionável a qualidade de algumas obras, mas não é o intuito discutir a estética dessas obras.

Faço mais uma ressalva quanto à classificação de Candido a respeito de criar categorias diferentes para classificar as temáticas regionais. Categorizar dessa forma nos leva a pensar uma linha fronteiriça onde se separa facilmente a arte do artesanato $^{5}$, é também dizer que o regional é incapaz de produzir grandes obras

5 Faço referência ao quadro de posicionamento dos objetos artísticos proposto por Clifford em "On collecting art and culture" no livro The predicament of culture, 1988. Segundo Clifford é tênue a linha que separa o objeto artístico do 'tourist art' (conhecido como artesanato no Brasil), em que os objetos 
literárias, e quando o faz e é aceito/a o escritor/a é levado "a aceitar o convite do colonizador à identidade: 'Você é um médico, um escritor, um estudante, você é diferente, você é um de nós"” (Bhabha, 1998, p.76).

Colocando de lado os estudos literários para enfim entrar no discurso da literatura goiana, trataremos desta como produção discursiva, como um dos inúmeros elementos de construção de identidades. Como vimos, alguns dos escritores regionais tinham o compromisso com "dizer a verdade da região" e se apoiavam no fato de serem goianos para legitimar seus discursos. Apesar do seu local de enunciação, "ideologicamente essas narrativas estão comprometidas com o ideário nacional” (LIMA, 2006, p.156). A literatura regional continua a reproduzir a perspectiva na qual o sertão é visto através de formas dicotômicas, pares antagônicos, como sertão/litoral, campo/cidade, atraso/modernidade, tradição/civilização, cidade do interior/capital. Essas parelhas, essa comparação de temporalidades e lógicas diferentes cria o sertão como alteridade, e por isso o cria como lugar "do que não deve ser", da outridade, daquilo que não é a norma. Algumas recorrentes representações do sertão na literatura, e também nos discursos hegemônico da nação, são as de construir o sertão como lugar vazio, fronteira a ser ocupada e civilizada, local de formas arcaicas de poder político (do coronelismo e seus jagunços), o sertão marcado pelas relações personalistas, todas essas formas remetendo ao sertão como tragédia, local de mazelas e determinismos ambientais.

Entretanto, a literatura regionalista goiana se diferencia e se assemelha a outros escritos regionais. Segundo Vicentini (2008), o sertão goiano foi narrado, principalmente, através de temáticas como o gado, a mineração e o bandeirantismo (temáticas que coincidem, apesar de serem representadas de forma diferente, da dos sertões de São Paulo, Minas Gerais e Mato Grosso). A perspectiva do bandeirantismo coloca o sertão como fronteira de expansão, lugar a ser conquistado e povoado, cultural e economicamente. Um exemplo é o livro de Hugo de Carvalho Ramos, Tropas e boiadas (2003), "uma reedição do bandeirantismo expressa na mobilidade literal do tropeiro e do gado e da produtividade econômica deste último" (p. 191). A figura do boiadeiro foi preferível à do roceiro na temática regionalista goiana. Historicamente, a figura do roceiro foi constituída como um estereótipo negativo associada ao pequeno camponês, o qual é visto como roceiro conformado, estagnado, o atraso que teria que 
sumir para dar espaço ao desenvolvimento da nação brasileira. Um exemplo na literatura do estereótipo do roceiro é a literatura sertaneja a partir do séc. XIX, que encenou o homem rural como preguiçoso, sentimental e animalesco, em personagens como o Jeca Tatu, de Monteiro Lobato.

Isso não quer dizer, entretanto, que o roceiro foi negligenciado pela literatura, mas que o gado se fixou na memória coletiva de forma mais arraigada, de modo que as pessoas lembram mais do Goiás do boi do que da lavoura. Um exemplo da temática do roceiro na literatura goiana é o conto de Bernardo Élis, A enxada ${ }^{6}$. No conto aparece a temática do roceiro, o pequeno agricultor em meio a relações clientelistas. Outra temática recorrente no sertão goiano é o coronelismo (Vicentini, 2008). Como exemplo literário temos o romance $O$ tronco, de Bernardo Élis que narra o enfrentamento político ocorrido na Vila do Duro, hoje Dianópolis(GO), entre duas famílias rivais $^{7}$, os Bulhões e os Caiados. O importante desse breve safári pela literatura regionalista goiana é mostrar como foi construída de forma deliberada a imagem sertanista do Estado, mas como nos alerta Bhabha: “imagem é apenas e sempre um acessório da autoridade e da identidade; ela não deve nunca ser lida mimeticamente como a aparência de uma realidade" (1998, p.85).

Goiás, como vimos até aqui, sempre foi objeto de interpretações e representações de tradicionalismos, atraso e toda espécie de aspectos negativos que podem ser agregados ao termo sertão. Porém o sertão não é um espaço físico delimitado, mas uma atribuição simbólica que pode adquirir uma consistência geográfica que é efêmera. Ele é uma região imaginada e um mito que narra a conquista da civilização pela nação brasileira. Não é um objeto reificado, é acima de qualquer coisa mobilidade, o sertão se desmancha no ar. Esse caráter móvel permite que o sertão seja ressignificado e até mesmo deslocado de certas regiões para que estas possam construir uma auto-imagem nos "modelos da modernidade", como é o caso de Minas e Goiás. É para essa representação do moderno em Goiás que gostaria de chamar a atenção. A política presente a partir dos anos 30 do século passado vai colocar a construção de Goiânia como marco da modernização do Estado através da integração à economia nacional.

Antes, contudo, queria fazer a ressalva de que apesar do "moderno" não ser

6 Um dos contos presente no livro Veranico de Janeiro de 1979.

7 Aparentadas por laços de casamento. Para mais informações ver Chaul (1997). 
temática recorrente na literatura regionalista, que sempre se preocupou com o rural, algumas imagens que não foram incorporadas pelo movimento de 30 são agregadas às representações de modernidade, como é o caso de Tropas e Boiadas, de Hugo de Carvalho Ramos. Como foi dito anteriormente, a imagem do boiadeiro foi construída associada ao progresso econômico, o boi como capaz de modernizar o Estado - espírito bandeirante do boiadeiro. Outro exemplo é o livro Jurubatuba (1997) de Carmo Bernades, no qual o personagem principal, Ramiro, é um boiadeiro esperto e trabalhador que coloca ordem moral e produtiva na fazenda onde trabalha. Ambos os romances têm em comum que os personagens personificam um espírito civilizador/modernizador, apesar da temática permanecer regional e vinculada ao campo.

Os discursos políticos da década de 30 retomaram e reforçaram a imagem do sertão como fronteira, o Goiás do crescimento econômico e de um novo país, com todos os atrativos de uma 'sociedade moderna'. Através de um ufanismo modernizador, se estabeleceu em Goiás o tempo novo, em oposição às 'velhas elites' políticas do Norte, entendidas como responsáveis pela manutenção do atraso. O Estado, apesar de se proclamar moderno, não rompe com as visões estereotipadas e negativas construídas. Pelo contrário, é através dessas concepções do Estado goiano que este vai se apoiar e legitimar sua auto-imagem "moderna". Como Chaul argumenta, "a representação da modernidade se efetivou, por meio de uma recuperação das imagens/conceitos da decadência e do atraso, como forma de justificar a deposição do 'velho Goiás' pelo movimento de 1930" (1997, p.20). É nas imagens do atraso que a ideologia da modernização ganha força. Apoiando-se no caráter de ruptura, o governo de Pedro Ludovico Texeira foi o porta voz na propagação desta representação. As narrativas de Goiás como atraso são retomadas para contrastar com o tempo do novo, do moderno, do progresso: "Esse imaginário salvacionista, que marcou o projeto brasileiro de modernidade, apresentava-se a Goiás como a redenção de um tempo que estava mergulhado em décadas de miséria e penúria" (Chaul, 1997, p.21).

Essa representação colocava as elites do sudoeste goiano como modernizadoras de Goiás. O Sudoeste sempre se destacou pela produção agrícola, ao contrário do Norte onde o gado prevaleceu como atividade econômica. Com a chegada dos trilhos em 1913 o Sudoeste se desenvolve devido à possibilidade de exportação agrícola, antes inviável por causa das más condições das estradas. Até 1930 não foi possível a essas elites fazer parte do governo, restrito às elites do Norte. Com a ascensão 
de Getúlio Vargas, as velhas elites políticas são destituídas do poder sobre o pretexto de se modernizar o país colocando fim à "república dos coronéis". Abraçando a causa nacional, Pedro Ludovico Texeira é expressão goiana do esforço modernizador da nação brasileira, presente como política de Estado.

A modernização que é entendida como uma auto-imagem que o Sudoeste cria para si e que depois é difundida para todo o Estado, ao ponto da antiga representação ser trancafiada anos depois ao Estado do Tocantins: "realocando as características negativas do sertão - o isolamento, os índios, os jagunços, os coronéis, o atraso - para além de suas fronteiras estaduais, constituindo o Tocantins imediatamente numa alteridade da alteridade" (Sena e Lima, 2005, p.46). Em um estudo sobre as representações do Sudoeste goiano, Rodrigues (2006) fala sobre os escritores locais e a importância, destes, na construção do Sudoeste como espaço diferenciado do restante do Estado. Ora chamando o Sudoeste de centro-sul ou apenas fazendo a diferenciação norte-sul, esses autores fixaram na memória coletiva as migrações paulistas e mineiras como fundadoras da sub-região. Explicando sua supremacia cultural pela proximidade geográfica com Minas e São Paulo, o Sudoeste goiano, por sofrer maior influência desses Estados, estaria "mais [...] [propenso à] concentração de formas culturais 'avançadas"', em oposição ao Norte, que teria sofrido migrações principalmente de nordestinos (Rodrigues, 2006, p.59).

Esses autores ${ }^{8}$ reforçam a ideia de uma ligação cultural e econômica muito mais forte com o Triângulo Mineiro do que com o Estado de Goiás, antes da revolução de 30. Segundo eles, o contato com Minas possibilitou a essa região um maior contato com a "cultura brasileira", ao contrário do Norte que teria se mantido isolado geograficamente do restante do país - o país aqui tido como os centros da nação. E o isolamento do Sudoeste, em relação ao restante do Estado de Goiás, também é usado para reforçar a ideia de uma região que não compartilhou trocas culturais com Goiás, tendo se desenvolvido por causa da "qualidade da população e de seus líderes" sem nenhuma influência do Goiás-sertão. Segundo a autora do estudo: "É importante observar [...] que é a identidade mineira que é buscada como passado regional e não como sendo desde sempre parte de uma formação goiana" (Rodrigues, 2006, p.80 e p.81).

8 Como exemplos podemos citar autores goianos renomados como Basileu Toledo França e Gilberto Mendonça Teles. 
A modernização foi muito tratada por cientistas sociais e historiadores a nível nacional. Negligenciando a eficácia do processo de identificação regional esses autores partiam do pressuposto de que não existiria, no Brasil, questão regional: “A partir dos anos 50, a ascensão do capital monopolista teria subordinado todas as outras formas assumidas pelo capital, igualando e homogeneizando os espaços onde penetrava" (SENA, 2003, p.45) ${ }^{9}$. O regionalismo era visto como discurso ideológico das classes dominantes regionais, que utilizavam desse instrumento como forma de alienar e manter o poder. A principal característica de tais trabalhos era traçar um projeto de modernidade para o Brasil e trancafiar o regionalismo a um passado distante já superado, restando apenas vestígios de cunho ideológico que com o tempo iriam desaparecer.

Os historiadores e cientistas sociais de Goiás também trilharam caminhos parecidos. Dentre eles é popular a imagem do atraso e da decadência como descrição da sociedade goiana em oposição à modernização. Tanto Chaul(1997) como Rabelo(1998) em seus trabalhos - o primeiro numa revisão historiográfica, e o segundo sobre os trabalhos produzidos em ciências sociais nos anos 70, em Goiás - chamam a atenção para a recorrente interpretação desses intelectuais de traçar momentos de ruptura entre o tradicional e o moderno. Ao contrário do que Rabelo esperava, temáticas rurais não constituíram os principais estudos de cientistas sociais; ao contrário, era recorrente falar sobre a modernização/mudança de Goiás. $\mathrm{O}$ viés presente nesses trabalhos demarca espacialidades e temporalidades como momentos de mudança: a revolução de 30 , o desenvolvimento da educação, a construção da capital, etc tornam-se pontos de memória em que se apoia a perspectiva da modernidade. Foram produzidas modalidades discursivas que viam a modernização como fruto da ação externa, colocando a causa do desenvolvimento de Goiás como fruto da expansão agrícola do Triângulo Mineiro. Nota-se uma semelhança discursiva entre a produção dos escritores locais do Sudoeste e a produção acadêmica a respeito de Goiás. Podemos arriscar a interpretação de que a auto-imagem do Sudoeste se torna a auto-imagem do Estado, deslocando, como já foi dito, o atraso para o atual Estado do Tocantins.

$$
* * *
$$

Em uma etnografia com jovens universitários nascidos em Goiás a partir de

9 Sena refere-se à obra de Francisco de Oliveira, "Elegia pra uma re(li)gião: Sudene, nordeste e conflitos de classes", de 1971, mas aqui uso a fala da autora de forma generalizada para quase toda a produção que tratou da questão regional. 
1980, que vivem em Goiânia e cursam ciências sociais, podemos perceber a negociação agonística, a que Bhabha se refere, entre o pedagógico e o performático. Qual o alcance e como são negociadas essas imagens da modernidade e do sertão no imaginário dessas pessoas? Quais as implicações desse discurso? Essas são as perguntas que nos propomos a responder abaixo. Através de entrevistas abertas, pergunta-se a esses estudantes sobre o sertão, a história do Estado de Goiás, a cidade de Goiânia, a modernidade, família e tradições.

A partir das entrevistas interpretamos as falas dos entrevistados tendo em vista cinco eixos: o sertão; performatizando o sertão; memórias sobre Goiás; Goiânia, lócus performativo e de performance da modernidade; e a modernidade como inevitabilidade. Posteriormente promoveremos uma discussão em torno do contexto apresentado e a relação com a etnografia.

Quando se trata de sertão foi notado que embora os entrevistados tenham concepções diferentes do que seja, há coincidências geográficas na identificação dos lugares. Entre as representações encontradas podemos destacar o sertão enquanto bioma, herdado do discurso dos viajantes de província que retrataram a região principalmente através da paisagem só natureza, nesta perspectiva, o sertão aparece como paisagem agreste, ressequida e pobre e com clima semi-árido; ou ainda associa-se o sertão com as cidades de interior ou fazendas, onde há gado, árvores e casas antigas (lugar geográfico); ou como categoria de diferenciação entre o centro simbólico do Brasil, desenvolvido, e o sertão, atrasado (lugar imaginário); e por fim como local de crenças, costumes rurais, festas tradicionais e lugar de vida pacata (o sertão enquanto diferença cultural).

Apesar das representações encontradas serem inúmeras, os locais geográficos apontados como sertão não são tão variados. Geralmente são o Nordeste, partes de Minas Gerais, Mato Grosso, Mato Grosso do Sul, Goiás e Tocantins. Os últimos dois Estados merecem mais atenção pelo impacto que desempenham neste contexto. O Tocantins que até pouco tempo era território goiano se torna unidade federativa com a Constituição de 1988. Nas entrevistas pode-se notar que o Tocantins é percebido como diferenciado de Goiás, apesar da separação ser recente, pois o Tocantins ocupa a região norte daquilo que antes era o Estado de Goiás. O Tocantins se torna alteridade do Estado, pois para o primeiro foi deslocado o sertão de Goiás.

A partir da concepção de sertão dos entrevistados foram encontradas respostas que se distanciavam do sertão de duas maneiras: a primeira temporalmente, 
que designa o tempo de visitar fazendas e cidades do interior como parte da infância, mas não como prática atual; e outra culturalmente, que reconhece a prática de ir ao sertão, mas que se nega como parte dele ao realçar diferenças no estilo de vida, inclusive a falta de tecnologia. Os dois aspectos do discurso possuem em comum a renegação do sertão ao passado, o primeiro como passado histórico da vivência pessoal, o segundo enquanto resistência do passado no presente, mas ambos performatizam o sertão como tradição e não civilização.

Quando perguntados sobre história de Goiás é frequente se falar do contato dos Anhangueras com os índios, a economia mineradora e a construção de Goiânia. Chaul chama a atenção para a ideia de que a auto-imagem do desenvolvimento aparece em Goiás sempre em contraposição com uma época decadente (1997). Nas estórias do Estado aqui presentes aparecem essa mesma oposição, o discurso passadista é herdado para se opor a um tempo novo, que foi atribuído principalmente à construção da capital.

A construção de Goiânia é primordial na performatização da modernidade no Estado goiano. Ao falar sobre a cidade todos os entrevistados se mostram satisfeitos com ela. Todas as características da capital são usadas em prol da exaltação da modernidade. Quando comparada a outras cidades os discursos afirmam que Goiânia ocupa um lugar intermediário, uma cidade a meio caminho entre a modernidade e a tradição. Se por um lado Goiânia não tem muitos eventos culturais e oportunidades, como apontam os entrevistados, na cidade a violência é menor, a poluição é menor, a cidade é mais verde e ainda oferece todos os benefícios da modernidade, mesmo que pouco variados. Isso não tira a validade do discurso da modernidade, mas sim o reforça na medida em que este foi o meio encontrado para performatizar a modernidade através das particularidades locais, negociando certos aspectos presentes e justificando a civilização. Mas se a capital é performativa por si mesma, ela também é espaço de performances, as práticas sociais como ir a bares, fazer festas na casa de amigos, ou ir a shows, são colocadas como símbolos da modernidade. As festas nas casas de amigos, por exemplo, são utilizadas como justificativa para a ausência de variedade de programações na cidade, mas ao mesmo tempo reforça que os atores são modernos, o espaço é que não é. Eles admitem que existem programações culturais de interesse, só que não em número suficiente; mais uma vez a ideia de uma capital a meio caminho se faz presente, mas não invalida a representação de modernidade criada para si.

Quando perguntados sobre modernidade, e se vivem na modernidade, as respostas obtidas eram sempre afirmativas, apesar de negociadas. Assim como o sertão, 
a modernidade é vista por meio de uma variedade de imagens que vão desde a Revolução Industrial a uma mudança de valores, à diferença geracional, ou a um ritmo de vida acelerado. Apesar dessas diferenças, é consenso que a modernidade é fator inevitável de suas vidas. Por isso todos argumentam que estariam vivendo na modernidade, mesmo reconhecendo momentos de contradição, como os valores compartilhados na família, ou os valores da pessoa como antagônicos à modernidade. Para isso, todo um universo de práticas é utilizado de modo performativo para justificar a modernidade, ora associado às idas aos shoppings centers, ao visual, à forma de lidar com o trabalho, à universidade ou à falta de tempo.

A pesquisa apresentada acima procura entender como e em que medida os discursos constroem práticas, e como estas se performatizam. Primeiro, é importante relembrar que "as palavras e as coisas são independentes; a região se institui, paulatinamente, por meio de práticas e discursos, imagens e textos que podem ter, ou não, relação entre si, um não representa o outro" (Albuquerque Jr., 2001, p. 46). A performance social realizada através do discurso não pressupõe uma mudança nas práticas sociais, mas que certos enunciados se associam às práticas, e lhes atribuem valores tornando-as inteligíveis. Através de escolhas unilaterais sobre quais práticas se identificam ou não com certas identidades, criam-se enunciados performativos. A performance pode ser a maneira pela qual a repetição de enunciados "reforça o aspecto negativo atribuído à identidade", ou por outro lado reforça o aspecto positivo (Tadeu da Silva, 2007, p. 95). Segundo Pechincha, o "significado de um discurso nunca é ancorado numa essência - essa essência que ele mesmo quer representar. O significado está em jogo com a diferença dele mesmo e ele precisa ser constantemente reiterado para se manter frente ao que lhe difere" (2006, p. 23). O objetivo proposto aqui foi o de ver até que ponto o discurso que ganha respaldo a partir dos anos 1930 tem uma eficácia performativa de realocamento do sertão goiano para além de suas fronteiras e quais as estratégias de reiteração de tal discurso para dar sentido a uma ideologia hegemônica do Estado nacional. O que podemos ver nesses discursos e performances no e do estado de Goiás é que discurso e prática não têm uma relação de congruência entre si, eles não seguem uma regra coerente de associação; a performance aqui é aquela parte específica das infinidades de práticas que desempenhamos no dia a dia, que se unem a certo discurso para torná-lo performativo, produzindo uma identidade, no caso vinculada à modernidade, mas ainda assim uma identidade goiana fadada ao regionalismo.

Tendo em vista essa cisão entre identidade e práticas sociais, a análise 
etnográfica encontrada aqui procurou uma associação entre um discurso que tentou a reversão do estigma de sertão no estado de Goiás e as falas dos jovens aqui em questão. Podemos perceber que esse discurso interpela e produz uma congruência entre as falas desses alunos. O lócus da modernidade no Estado é visto através da cidade de Goiânia, deixando todas as outras áreas de Goiás de fora, atribuindo a elas o signo do sertão. Cria-se então alteridades de alteridades dentro do próprio Estado.

Também percebemos, contudo, que esse discurso não tem apenas um alcance limitado intra-estadual, mas também interestadual. Assim, apesar de ser representado por uma elite como o Estado que se "modernizou", no discurso hegemônico da nação, Goiás continua a ser uma região periférica, lugar vazio e fronteira de expansão. Por isso, os atores sociais estariam fadados, como já disse, a produzir manifestações regionalistas e particularistas. Porque a universalidade ainda se encontra no centro da nação, que não coincide com o centro do território do Brasil. Por outro lado, também não podemos fechar os olhos para políticas do Estado que vão atualizando essas representações e tornando-as legítimas, incorporando-as ao rol da hegemonia estatal. É o exemplo do mapa da nova regionalização do IBGE, que separa os grandes centros urbanos das áreas periféricas, legitimando essa representação de modernidade feita para Goiás. E esse translocamento do sertão não é um fenômeno apenas do Estado de Goiás, ele se expressa também na região nordeste, onde se tenta empurrar o sertão nordestino para o interior do Estado, proclamando a modernidade da costa-litoral, e dualizando a imagem unificada do Nordeste. No novo mapa da divisão regional, Tocantins aparece sem centros urbanos e como parte da região Norte, atrelando o desenvolvimento desse último Estado como de responsabilidade dos centros urbanos do Norte.

Assim, um discurso que não tinha hegemonia alcança-a aos poucos, à medida que é legitimado pelo Estado nacional. O que cria novas alteridades históricas, porque é na própria criação da nação enquanto narrativa de uma parcela dominante da sociedade nacional que são criadas as alteridades, os outros da nação (Segato, 2007). Ao se tornar "moderna", a região estaria em compasso com a nação. Porém, no momento de performatização da região, outras alteridades são criadas, reforçando assim o caráter plural e desmascarando o esforço totalizante da nação em interpelar sujeitos e esperar que produzam mimeticamente o discurso da nação. É por isso que Bhabha diz que a nação moderna tem um tempo duplo inconciliável, o pedagógico e o performático (Bhabha, 2007). Enquanto o primeiro se vincula ao que Segato chamou de Estado 
nacional, o segundo se refere aos sujeitos nacionais, a sociedade nacional, com toda sua diferença interna (2007).

Importante se faz lembrar também que a performance e o discurso da região se associam à hegemonia do discurso da "modernidade". A ideologia, entretanto, pode variar de conteúdo, se reconfigurando e reificando em contextos específicos, adquirindo novas caras que justificam o mesmo. Contudo, para se fazer inteligível ela tem que manter oculto o caráter localizado e particularista dessas ideologias, pressupondo-se universal. Dumont já chamava a atenção para essa faceta da ideologia:

As idéias e valores individualistas da cultura dominante, à medida que se propagam através do mundo, sofrem localmente modificações que dão origem a novas formas. Ora, e está aí o ponto inapercebido, essas formas modificadas ou novas podem passar, por sua vez para a cultura dominante e nela figurar como elementos modernos de pleno direito (Dumont, 200, p. 30)

O que se buscou aqui não foi traçar o que seria a modernidade para esses jovens universitários, mas sim procurar ver como essa modernidade é negociada em imagens desconexas e desesperadas para que estes se legitimassem como "modernos". E ao fazer esse movimento, tais atores sociais acabam reforçando e contribuindo para a permanência de um discurso hegemônico que é próprio da nação moderna. Discurso que ajuda e reforça a formação nacional de alteridades (Segato, 2007), silenciando "las márgenes - uno podría decir el cientro silente, silenciado - del circuito marcado por esa violencia epistémica, hombres y mujeres entre el campesinado iletrado, las tribus, y los más bajos estratos del subproletariado urbano" (Spivak, 2003, p. 320-1).

A presente etnografia não teve uma finalidade essencialista, delimitando e associando discurso e prática. Procuramos argumentar como esse regionalismo se agrega a um discurso hegemônico nacional - reconhecendo-o ou não - e como essa estratégia de reversão do estigma não resolve o problema das alteridades históricas nacionais, mas sim os reforçam e os recriam. 


\section{Referências Bibliográficas}

ANDERSON, Benedict. Comunidades imaginadas: Reflexões sobre a origem e a difusão do nacionalismo. São Paulo: Companhia das letras, 1997.

BERNARDES, Carmo. Jurubatuba, Goiânia: Ed. da UFG. 1997.

BHABHA, Homi k. O local da cultura. Belo Horizonte: Editora UFMG, 2007.

CANDIDO, Antonio. Literatura e sociedade. São Paulo: Nacional, 1967

CHAUL, Nasr fayad. Caminhos de Goiás: da construção da decadência aos limites da modernidade. Goiânia: Editora UFG, 1997.

CLIFFORD, James. The Predicament of culture. Cambridge, Massachussets, and London, England: Harvard University Press, 1988.

DE ALBULQUERQUE JR, Durval Muniz. A invenção do nordeste e outras artes. São Paulo: Ed Cortez; Recife: Ed. Massanga, 2001.

DUMONT, Louis. O Individualismo: Uma perspectiva Antropológica da Ideologia Moderna. Rio de Janeiro: Rocco, 2000.

DUSSEL, Enrique. 2004. "Sistema mundo y transmodernidad". En: Saurabh Dube, Ishita Banerjee y Walter Mignolo (eds.). Modernidades coloniales. México: El Colegio de México.

ELIS, B. Veranico de Janeiro. $4^{\text {a }}$ ed. Ed. Rio de Janeiro: José Olympio, 1979.

ÉLIS, Bernardo. O Tronco. Rio de Janeiro: José Olimpio, 1979.

FANON, Franz. Los condenados de la tierra. México, D.F.: Fondo de Cultura Economica, 1986.

JOHNSON, Richard. O que é afinal estudos culturais?. In: Tomaz Tadeu da Silva (org.) O que é afinal estudos culturais? Belo Horizonte: Autêntica, 2006

LIMA, Nei Clara. Os crespos do sertão. O Público e o Privado, Fortaleza, n.7, vol.1, jan./jun. 2006.

PECHINCHA, Mônica Thereza Soares. O Brasil no discurso da antropologia nacional. Goiânia: Cânone Editorial, 2006.

QUIJANO, Anibal. Colonialidade do poder, eurocentrismo e América Latina. Lander, E. (org.). A colonialidade do saber: eurocentrismo e ciências sociais. Buenos Aires: clacso, 2005.

RABELO, Francisco Evangelista. Desenvolvimento e identidade: parâmetros da reconstrução das ciências sociais e humanas. Sociedade e Cultura, Goiânia, n.1, vol.1, jan./jun., 1998. 
RAMOS, Hugo de Carvalho. Tropas e boiadas. Rio de Janeiro: Lacerda Ed., 2003.

RODRIGUES, Cinthya Maria Costa. A região da aldeia: os pressupostos geográficosespaciais da literatura goiana e a construção do Sudoeste de Goiás. In: O Público e o Privado, Fortaleza, n.7, vol.1, jan./jun. 2006.

RUTHERFORD, Jonathan e BHABHA, Homi. O terceiro espaço: uma entrevista com Homi Bhabha. Em Rutherford (org.), Identity-community, cultutre, difference. Londres: Lawrence \& Wishart, 1990.

SEGATO, Rita Laura. "Introdución", "Identidades Políticas/Alteridades históricas: uma crítica a las certezas del pluralismo global”. Em: La Nación e sus Otros. Buenos Aires: Prometeo Libros, 2007

SENA, Custódia Selma e LIMA, Nei Clara. Regiões e regionalismos. Em Moura e Sena (orgs.) Cidades: relações de poder e cultura urbana. Goiânia: Editora Vieira, 2005.

SENA, Custódia Selma. Interpretações dualistas do Brasil. Goiânia: Editora UFG, 2003.

SPIVAK, Gayatri Chakravorty. Puede Hablar el Subalterno? Revista Colombiana de Antropologia, Colombia, Volumen 39, enero-deciembre 2003, pp. 297-364.

SUÁREZ, Mireya. Sertanejo: um personagem mítico. Sociedade e Cultura, Goiânia, n.1, vol.1, jan./jun., 1998.

TADEU DA SILVA, Tomaz. A produção social da identidade e da diferença. In: TADEU DA SILVA, Tomaz(org.) Identidade e diferença: A perspectiva dos estudos culturais. Petrópolis: Editora Vozes, 2007.

VICENTINI, Albertina. O sertão e a literatura. Sociedade e Cultura, Goiânia, n.1, vol.1, jan./jun., 1998.

VICENTINI, Albertina. Regionalismo literário e sentidos do sertão. Sociedade $e$ cultura, Goiânia, n.2, v.10, jul./dez. 2008.

\section{Sites:}

IBGE. Mapa: Divisões regionais do Brasil- 2006. Disponível em: fttp://geoftp.ibge.gov.br/mapas/tematicos/mapas_murais/brasil_divisoes_regionais_200 6.pdf Acessado em 28 out 2009. 